\title{
Characterization of the Complete Nuclear Ribosomal DNA Sequences of Paramphistomum cervi
}

\author{
Xu Zheng, ${ }^{1}$ Qiao-Cheng Chang, ${ }^{1}$ Yan Zhang, ${ }^{1}$ Si-Qin Tian,, ${ }^{1}$ Yan Lou, ${ }^{1}$ Hong Duan, \\ Dong-Hui Guo, ${ }^{1}$ Chun-Ren Wang, ${ }^{1}$ and Xing-Quan $\mathrm{Zhu}^{1,2}$ \\ ${ }^{1}$ College of Animal Science and Veterinary Medicine, Heilongjiang Bayi Agricultural University, Daqing, \\ Heilongjiang 163319, China \\ ${ }^{2}$ State Key Laboratory of Veterinary Etiological Biology, Key Laboratory of Veterinary Parasitology of Gansu Province, \\ Lanzhou Veterinary Research Institute, Chinese Academy of Agricultural Sciences, Lanzhou, Gansu 730046, China
}

Correspondence should be addressed to Chun-Ren Wang; chunrenwang@sohu.com and Xing-Quan Zhu; zhuxingquan@caas.cn

Received 11 February 2014; Accepted 16 June 2014; Published 20 July 2014

Academic Editor: Rajesh Jeewon

Copyright @ $2014 \mathrm{Xu}$ Zheng et al. This is an open access article distributed under the Creative Commons Attribution License, which permits unrestricted use, distribution, and reproduction in any medium, provided the original work is properly cited.

\begin{abstract}
Sequences of the complete nuclear ribosomal DNA (rDNA) gene from five individual Paramphistomum cervi were determined for the first time. The five complete rDNA sequences, which included the $18 \mathrm{~S}$ rDNA, the internal transcribed spacer 1 (ITS1), the $5.8 \mathrm{~S}$ rDNA, the internal transcribed spacer 2 (ITS2), the $28 \mathrm{~S} \mathrm{rDNA}$, and the intergenic spacer (IGS) regions, had a length range of 8,493-10,221 bp. The lengths of the investigated 18S, ITS1, 5.8S, ITS2, and $28 \mathrm{~S}$ DNA sequences, which were 1,994 bp, 1,293 bp, $157 \mathrm{bp}, 286 \mathrm{bp}$, and 4,186 bp, respectively, did not vary. However, the IGS rDNA sequences had a length range of 577-2,305 bp. The $5.8 \mathrm{~S}$ and ITS-2 rDNA sequences had 100\% identity among the five investigated samples, while the identities among the IGS had a range of 53.7-99.8\%. A comparative analysis revealed that different types and numbers of repeats were found within each ITS1 and IGS region, which may be related to the length polymorphism of IGS. The phylogenetic position of $P$. cervi in Paramphistomatidae was analyzed based on the $18 \mathrm{~S}$ rDNA sequences. These results will aid in studying the intra- and interspecific variation of the Paramphistomatidae and the systematics and phylogenetics of Digenea.
\end{abstract}

\section{Introduction}

Paramphistomum cervi (Trematoda: Digenea: Paramphistomatidae), the representative species of the genus Paramphistomum, has adult flukes that customarily inhabit the rumen and immature worms that parasitize the gallbladder and reticulum of ruminants, including cattle, sheep, goat, and some wild mammals $[1,2]$. Although the adult $P$. cervi is relatively less pathogenic, acute gastroenteritis can occur in young animals when several immature worms migrate through the intestine to the rumen [3-5]. P. cervi is distributed worldwide and has been reported in many countries [1-6]. In China, Heilongjiang Province is the main endemic region [7].

Previous studies on $P$. cervi have mainly focused on morphology, life history, and epidemiology [1-7]. There are only a few molecular level studies on P. cervi. Recently, the complete mitochondrial DNA sequence and the ITS2 rDNA sequence of $P$. cervi were determined $[8,9]$. The nuclear ribosomal DNAs (rDNAs) of eukaryotes are arranged into tandem repeats. Each repeat has a transcriptional unit containing three genes (18S, 5.8S, and 28S rRNA) with two internal transcribed spacers (ITS1 and ITS2) separating these genes and an intergenic spacer (IGS) between the transcriptional units [10]. Different rDNA regions evolved at different rates; therefore, they can be used as genetic markers for phylogenetic studies at different taxonomic levels. The ITS rDNA sequences provide useful genetic markers for parasite identification [11-14]. IGS rDNA contains some repeat sequences that cause considerable amounts of intraand interspecific variation in parasites [15]. However, the IGS region of parasites is relatively poorly characterized.

To identify novel genetic markers for studying intraand interspecific variation in the Paramphistomatidae and to 
TABLE 1: Primers used to amplify the complete rDNA sequence of Paramphistomum cervi. The upper and lower sequences are forward (F) and reverse $(\mathrm{R})$ for each primer, respectively.

\begin{tabular}{|c|c|c|c|c|}
\hline Name of primer & Amplification regions & Primer sequence $\left(5^{\prime}-3^{\prime}\right)$ & Annealing temperature $\left({ }^{\circ} \mathrm{C}\right)$ & Length \\
\hline \multirow{2}{*}{ P1 } & \multirow{2}{*}{$18 \mathrm{~S}$} & F: TCTGTGATGACTCTGGAT & \multirow{2}{*}{53.7} & \multirow{2}{*}{$1,596 \mathrm{bp}$} \\
\hline & & R: ACCATTCAATCGGTAGTA & & \\
\hline \multirow{2}{*}{ P2 } & \multirow{2}{*}{$18 \mathrm{~S}-28 \mathrm{~S}$} & F: CACCGCCCGTCGCTACTACC & \multirow{2}{*}{55.2} & \multirow{2}{*}{$1,303 \mathrm{bp}$} \\
\hline & & R: TACTTTTCAАСТTTСССТСA & & \\
\hline \multirow{2}{*}{ P3 } & \multirow{2}{*}{$28 \mathrm{~S}-1$} & F: TAGGCAATGTGGTGTT & \multirow{2}{*}{54.7} & \multirow{2}{*}{$1,156 \mathrm{bp}$} \\
\hline & & R: TTGCACGTCAGAATCGCT & & \\
\hline \multirow{2}{*}{$\mathrm{P} 4$} & \multirow{2}{*}{$28 \mathrm{~S}-2$} & F: CGGAGACGGCGGCTTGTTGTG & \multirow{2}{*}{57.1} & \multirow{2}{*}{$1,608 \mathrm{bp}$} \\
\hline & & R: GGCTGTTCACCTTGGAGA & & \\
\hline \multirow{2}{*}{ P5 } & \multirow{2}{*}{$28 \mathrm{~S}-3$} & F: ACAGAGACGGGGTGCCTG & \multirow{2}{*}{51.7} & \multirow{2}{*}{$1,390 \mathrm{bp}$} \\
\hline & & R: AAAATCAAAATCAAGTAA & & \\
\hline \multirow{2}{*}{ P6 } & \multirow{2}{*}{ 28S-18S (IGS) } & F: TACCACCACCGTCATTGTTTCTTTG & \multirow{2}{*}{55.7} & \multirow{2}{*}{$1,742 \mathrm{bp}$} \\
\hline & & R: AAGTTATCCAGAGTCATCACAGAGT & & \\
\hline
\end{tabular}

further study the systematics and phylogenetics of Digenea trematodes, the present study determined and characterized the complete rDNA sequence of $P$. cervi, studied the intraspecific variation, and reconstructed the phylogenetic relationship of $P$. cervi within the family Paramphistomatidae.

\section{Materials and Methods}

2.1. Parasites and DNA Extraction. Adult P. cervi flukes were collected from the rumen of naturally infected cattle in Qiqihaer, Heilongjiang Province, China. Five adult flukes were washed extensively with physiological saline and identified to the species level based on morphological features described previously [2]. Total genomic DNA was extracted from five individual adult samples using the TIANamp Genomic DNA Kit (TIANGEN, Beijing, China) according to the manufacturer's instructions and eluted into $50 \mu \mathrm{L}$ doubledistilled water. The obtained DNA samples were stored at $-20^{\circ} \mathrm{C}$ until use.

2.2. Amplification, Sequencing, and Assembling of Complete rDNA Sequences. Six pairs of primers were designed based on the multiple alignments of Carmyerius spatiosus (JX518972, JX518958), Fischoederius elongatus (JX518979, JX518966), Gastrothylax crumenifer (JX518984, JX518969), Schistosoma haematobium (AY157263), S. japonicum (AY157607), and S. mansoni (AY157173) rDNA sequences available in GenBank. The primer sequences are listed in Table 1.

PCR reactions of $25 \mu \mathrm{L}$ contained $1 \mu \mathrm{L}$ DNA template, $5 \mu \mathrm{L}$ of $5 \times$ colorless Go Taq flexi buffer ( $\mathrm{pH} 8.5$ ), $2 \mu \mathrm{L}$ of $\mathrm{MgCl}_{2}(25 \mathrm{mM}), 2 \mu \mathrm{L}$ of dNTP Mixture $(2.5 \mathrm{mM}), 0.5 \mu \mathrm{L}$ of each primer $(10 \mathrm{pmol} / \mu \mathrm{L})$, and $0.2 \mu \mathrm{L}$ of Go Taq DNA polymerase $(5 \mathrm{U} / \mu \mathrm{L})$. The reactions were performed in a thermocycler under the following conditions: $95^{\circ} \mathrm{C}$ for $2 \mathrm{~min}$ (initial denaturation), followed by 35 cycles of $95^{\circ} \mathrm{C}, 1 \mathrm{~min}$ (denaturation), $51.7-57.1^{\circ} \mathrm{C}$ for $1 \mathrm{~min}$ (annealing), $72^{\circ} \mathrm{C}(\sim$ $1 \mathrm{~kb}$ region) for $1 \mathrm{~min}$ (extension), and a final extension of $72^{\circ} \mathrm{C}$ for $5 \mathrm{~min}$. Each amplicon was examined in a $1.0 \%$ (w/v) agarose gel, stained with ethidium bromide (EB), and photographed upon transillumination. The DL2000 marker was used to estimate the sizes of the rDNA amplicons. Representative PCR products were sent to Life Technology Company (Beijing, China) for sequencing using the same primers used in the primary amplifications. The five complete rDNA sequences of $P$. cervi were assembled using DNAStar software.

2.3. Sequence Analyses and Reconstruction of Phylogenetic Relationships. The $5^{\prime}$ and $3^{\prime}$ ends of the 18S, ITS1, 5.8S, ITS2, 28S, and IGS rDNA sequences of $P$. cervi were initially determined by comparing them with previously published rDNA sequences of other trematodes. For example, the $5^{\prime}$ end of $18 \mathrm{~S}$ and the $3^{\prime}$ end of $28 \mathrm{~S}$ were established by a comparison with the $S$. japonicum sequence [15], the $5^{\prime}$ termini of ITS1 and 5.8S were established by a comparison with Paragonimus kellicotti (HQ900670) and Echinostoma revolutum (GQ463130), respectively, and the $5^{\prime}$ termini of ITS2 and 28S were determined by referring to a previous study on $P$. cervi isolated from Slovakia (HM026462) [9]. Sequences of these rDNA regions from different individual adult fluke were aligned separately using Clustal X 1.83 [16]. The intraspecies sequence variation in each of these rDNA regions among the five individual adults and the interspecies sequence differences of the ITS2 rDNA within the family Paramphistomatidae were determined using the MegAlign procedure in DNASTAR 5.0 [17]. The base composition, transitions, and transversions were calculated using Mega 4.0 [18]. The characteristics of the ITS1 and IGS rDNA of $P$. cervi were examined using the palindrome program in EMBOSS 6.3.1 [19] (http:// mobyle.pasteur.fr/cgi-bin/portal.py?\#forms::palindrome) to find inverted repeats and REPFIND [20] (http://cagt.bu.edu/ page/REPFIND_submit) to identify direct repeats. These repeats were determined using the criteria of a nuclear match $\geq 10$ bp and a mismatch $\leq 1$.

The phylogenetic relationship of $P$. cervi with other trematodes was reconstructed based on $18 \mathrm{~S}$ rDNA sequences, using Taenia solium (GQ260091) as the outgroup. A maximum parsimony (MP) analysis was performed using the PAUP 4.0 Beta 10 program [21], and 1,000 random additional searches 


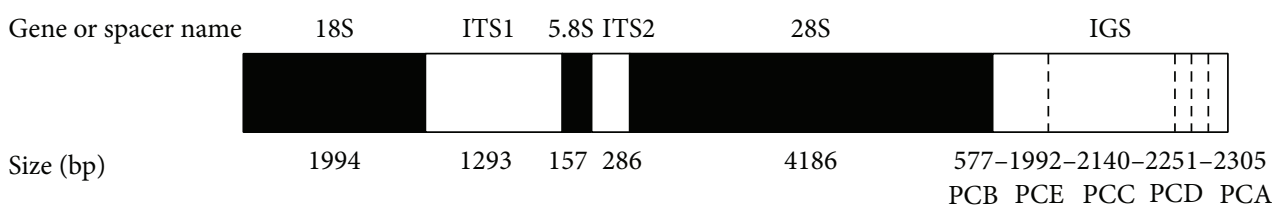

FIGURE 1: Organization of rRNA genes and spacers in Paramphistomum cervi. Dark shading indicates genes, light shading indicates spacers, and dashed bars in spacers indicate five lengths of IGS sequences.
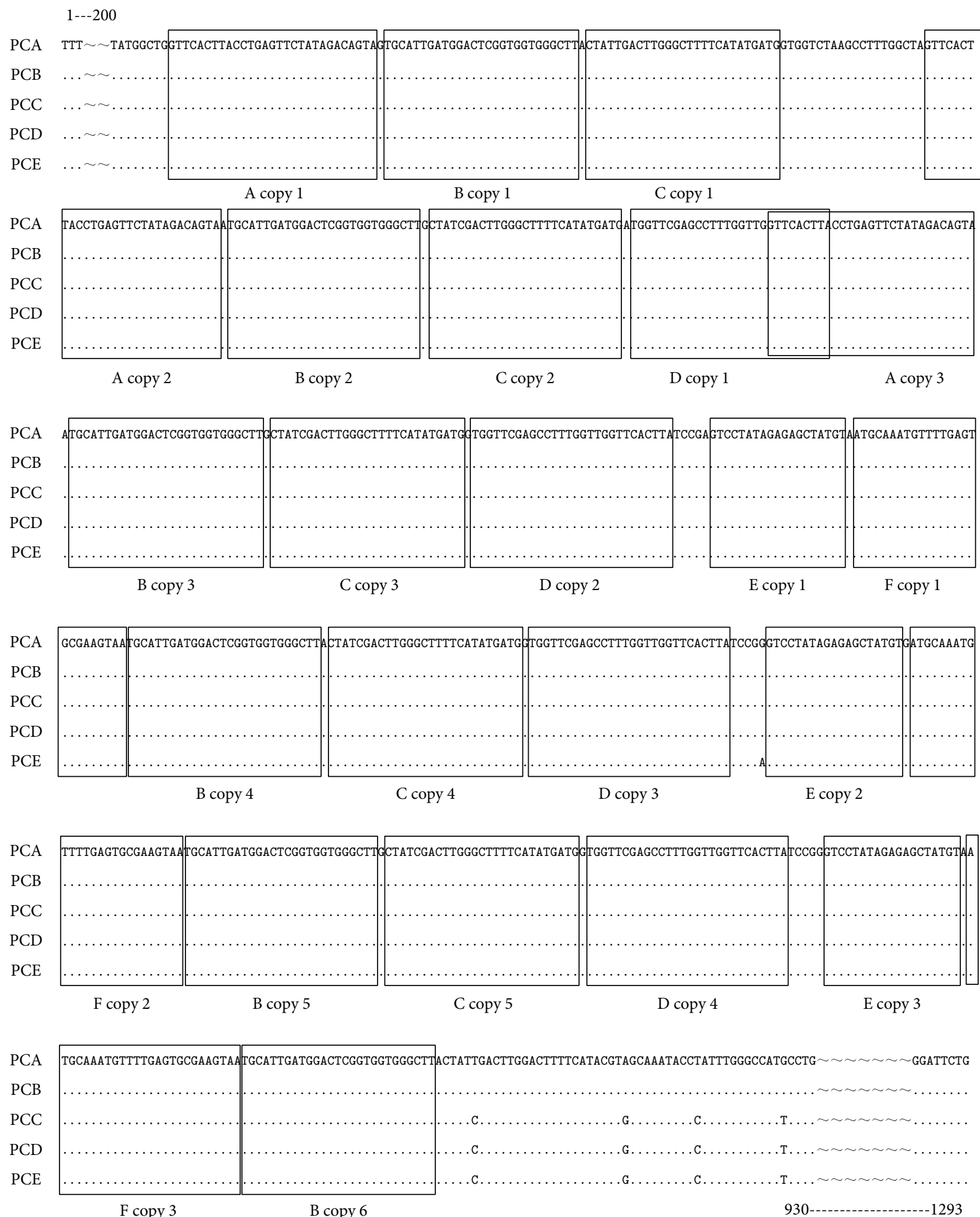

Figure 2: The alignment of ITS1 rDNA region of the five samples of Paramphistomum cervi. Dots denote sequence identity to the first sequence. Dashes represent nucleotide deletions. 
PCA GGGCTTGACTCTCATTCATTTG--TTATGTTCGCTATTGCAGTGAACGCGAAAAGATGGTAACGTGTGTGGACAAGCTATACGGTTGGCTTGGCTGTTGTCTCGGCTATTTGCCCCGGAC 120

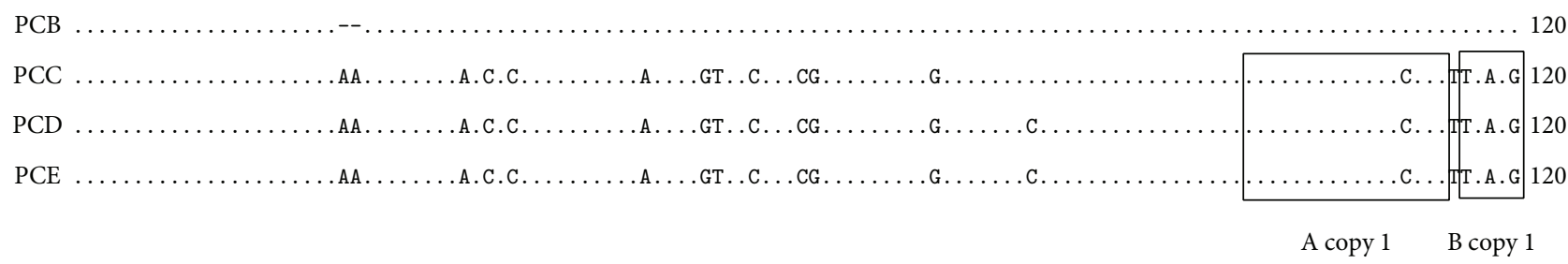

J copy 1

J copy 2

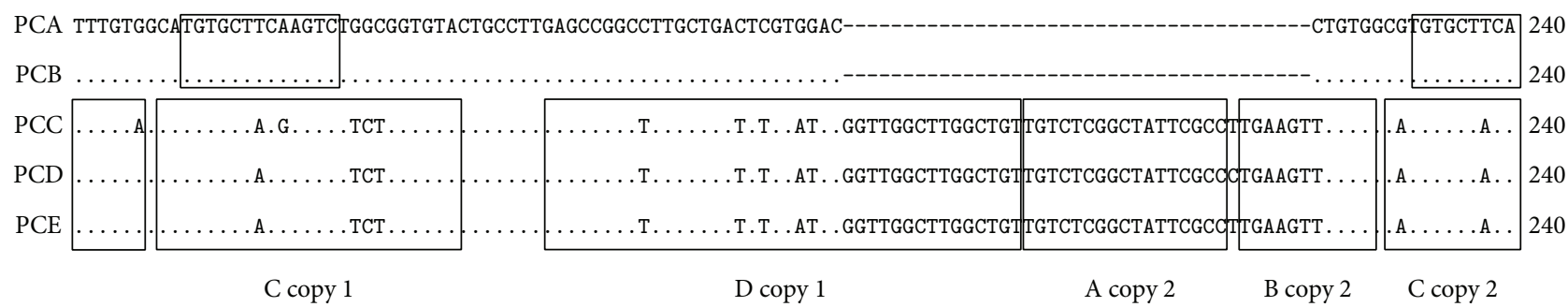
K copy 1
L copy 1
$\mathrm{N}$ copy 1

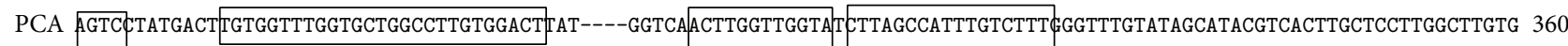

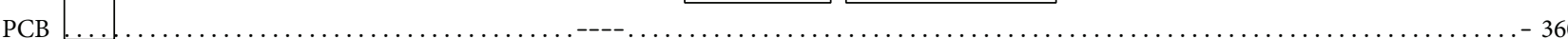

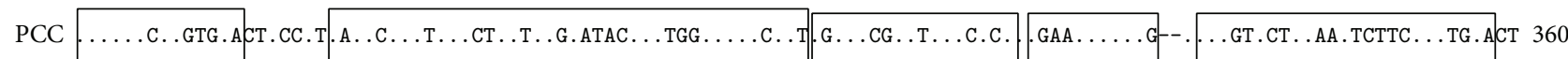

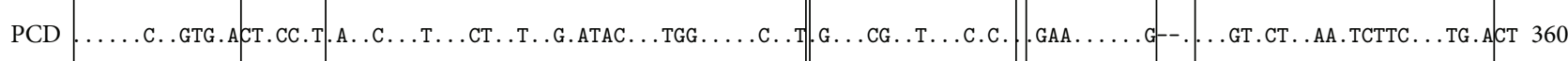

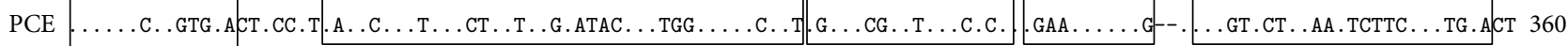
$\begin{array}{llll}\text { D copy } 2 & \text { A copy } 3 & \text { B copy } 3 & \text { C copy } 3\end{array}$
L copy 2
$\mathrm{N}$ copy 2
Q copy 1
K copy 2

PCA GTTTGATGCTGGCCTTGTGGACTTGT----GGTCAACTTGGTTGGTACETTAGCCATTTGCCTTI GGGTTTGTATCGTGTACGTTACTTATCCTTTGGCFIGTGGTTTGGTGCTGGCCTT 480 PCB

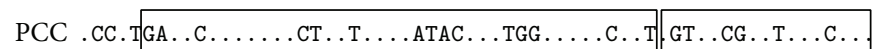

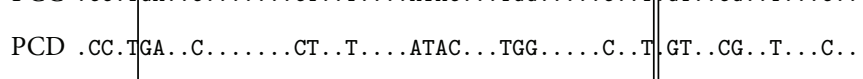

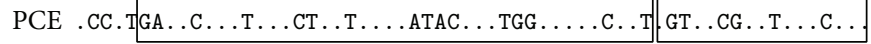

$$
\begin{array}{llll}
\text { D copy } 3 & \text { A copy } 4 & \text { B copy } 4 & \text { C copy } 4
\end{array}
$$
L copy 3
N copy 3
Q copy 2
K copy 3

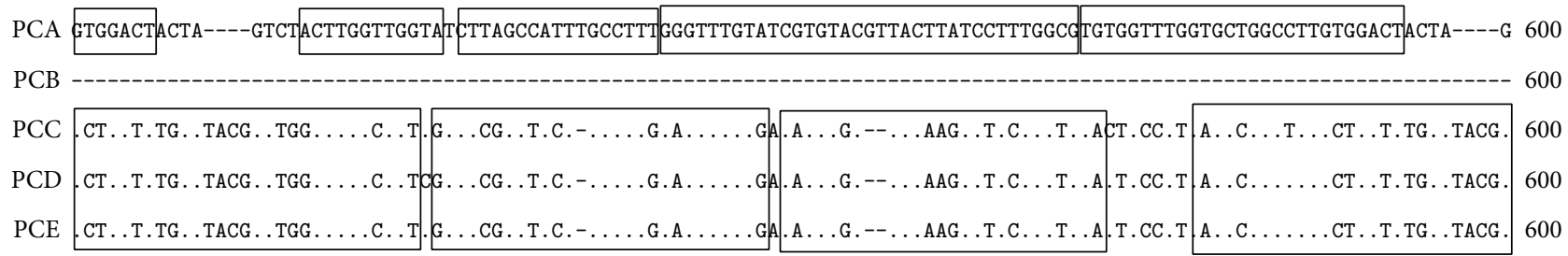
D copy 4

E copy 1

C copy 5

D copy 5

(a)

Figure 3: Continued. 
$\begin{array}{lllll}\text { L copy } 4 & \text { N copy } 4 & \text { K copy } 3 & \text { L copy } 5\end{array}$

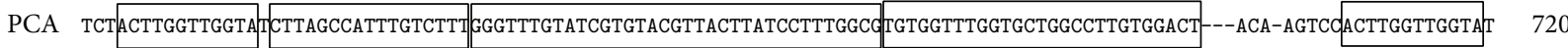

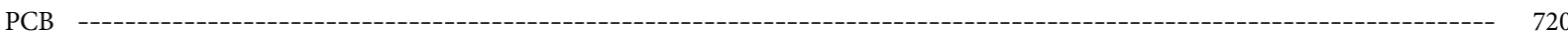

PCC
PCD

N copy 5

PCA ETTAGCCATTTGTCTTGGGATTTGTGTTGTATGTGTTGCTAGGCCTGTTGCAGGTGTTGCTATGTCACCCCCCCAATGGTATAAAGTGGTAATTTCCGTTAACACCCCTTCACTCAAAAC

PCB

PCC
PCD
PCE

R copy 1

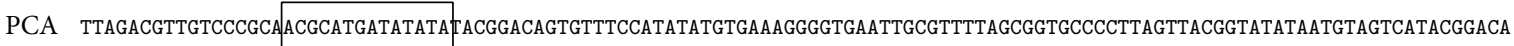

$\mathrm{PCB}$

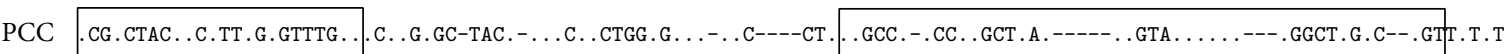

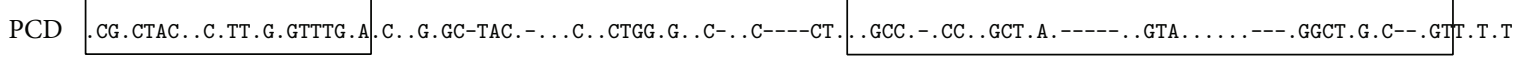
960

PCE ---ACTCC.AC. .GAG.G.TTG.A. .---CGC-T------.C. . . . . . . .

E copy 2

D copy 8

PCA TGGCAACCGGCAGGGAATTTGAAATCCCCCTGTGACATGTATATTGTACGCATGGCAACTGAGAGGTGGAGGGAAACGACCACTGCAGTGGCCACAGTAAACGGGGGTGGCGATGGTAAC

PCB 1080

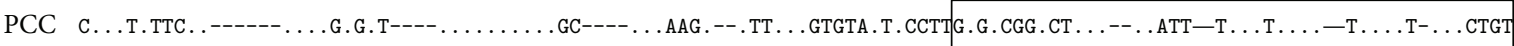

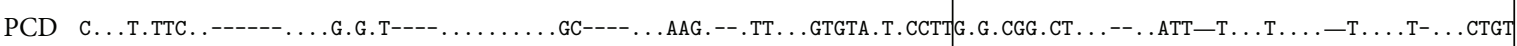
PCE --------TCA.-------.----GG.T----. AC. .G.G.-----------.AG--------_...GT. .-..CCTT-------.T.CAT--...-----T. -.T. .T. -T.AC.T-.------ 1080

\section{D copy 9}

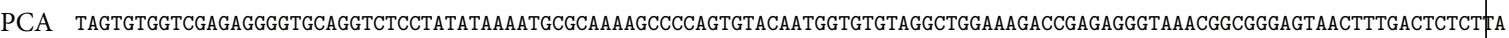

PCB 1200

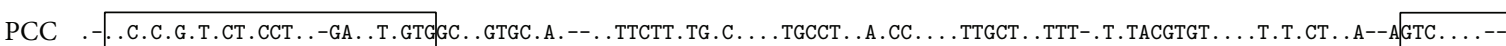

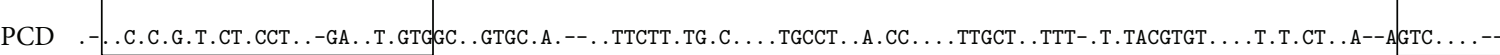

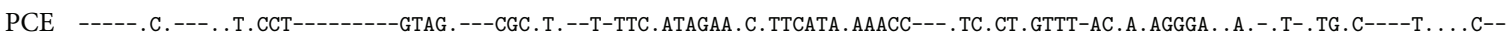
E copy 3

S copy 1 T copy 1

PCA AGgTGTTCAAACTG-TGCAAGTCATTTGCACTGTGTGCATCTTCTATATAAAAACCCGAGCTCTCAGGTTTTCCATGTAAAATAGCTATGACGCTCTTGATAGGGTGTGTGTGTGTGTGA 1320

PCB

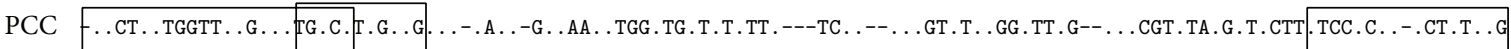
1320

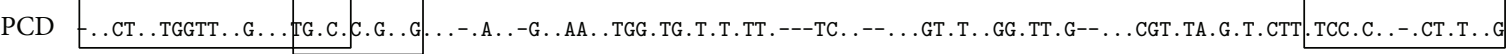
1320

PCE -A-T.GTG.--.AC. .TT.-C.T..C.AGTG-CC . TA . . CGCT-T . TT----TC. . -- .---------AG . . GC. -- .- . . . TATAAACC-----T. CAC. .- . . T . AC. . F copy $1 \quad$ G copy 1 
T copy 2

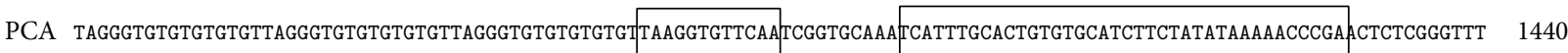

PCB

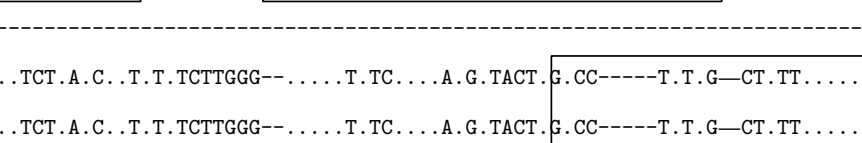
1440

PCC

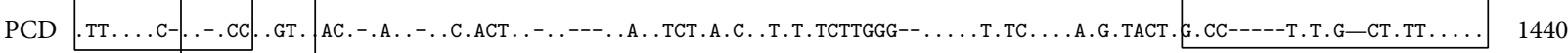

PCE G....A.G-A.-..T.----.CC.-.C.---CC.-T..------..A..-C....-.C.-TCT.G.G-------TG.C-_..A-_..GCT.-C.-----TTTC.--.AGAA.CA.C 1440

$\begin{array}{lll}\text { F copy } 2 & \text { G copy } 2 & \text { F copy } 3\end{array}$

R copy 2

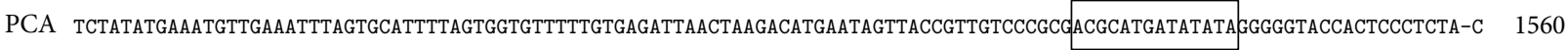

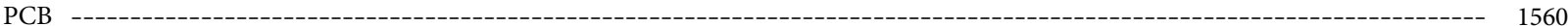

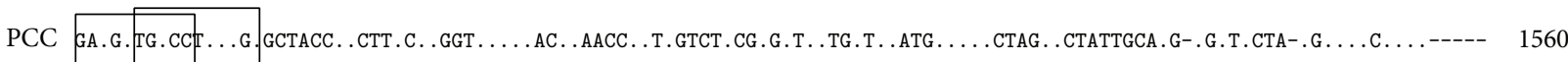

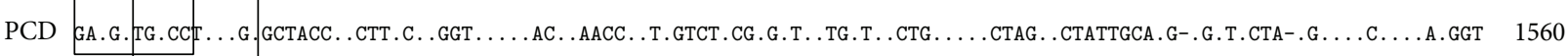

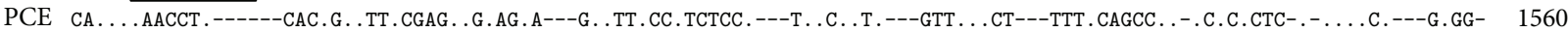
G copy 3

U copy 1

PCA ACGGACGATTGTTACCACTGTATATTTTACAGTGTTCAGGCATCGTTGTTCATTCGATGTGTTTGAAA-ACACAGACGCGATGACCTCGAGGACTTGGCTIGCTCCGGCC-GTTTAGATG 1680 $\mathrm{PCB}$

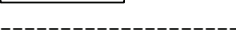
1680

PCC -TAA....GT. . - 1680

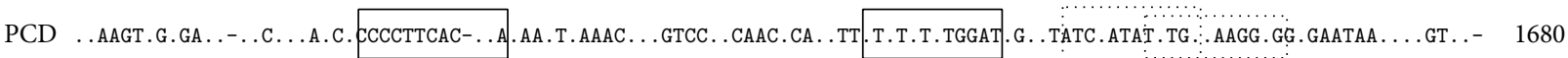
PCE -----------------------------------------------------------------_..................................G... 1680 $\mathrm{P}$

\section{$\mathrm{U}$ copy 2}

PCA TAATGTGGCGGCTTTGGTGAGCAAACC-TGCTTTGAGTGGAACGTGTCGTTCGGTCAAATGGGTTCAGGCGTGAATATATAGGCTGCCGGATTTTGGTATGCTCCGGCCATTTCGGCTAT 1800 PCB

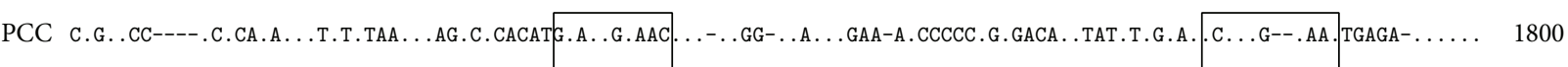

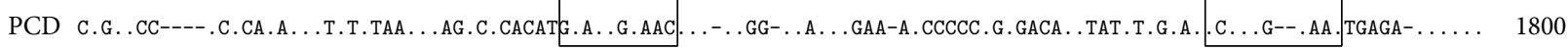

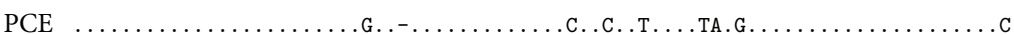

I copy 1

\section{I copy 2}

PCA ATGCACGGCCCCGATGGACATACCTATCCGATCCTACGGTATTTGGCTTAAATGGGCCTTAGCGGTTGTGTACTGGTTGGCTCTGGGCGCGTTATGCTCAGGGCCACGAAGTAGCCGCAT 1920 PCB

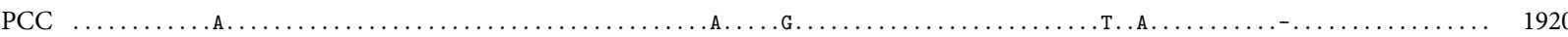

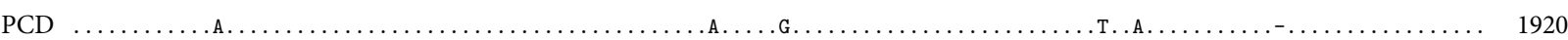

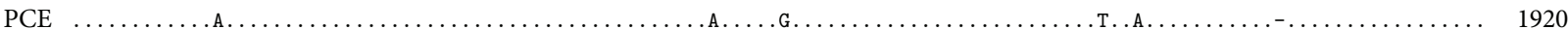

V copy 1

PCA TTGAATGTAAGTCGTGCCTGTTGCTGGTGGCAACACCACAATGGGCTGAGCTTACTTGTGTGGGTGACGGGTTCTCTGAATCATTCATTCTGTGAGGGGCAGTAGCGTGCTTCGTGAGTG 2040

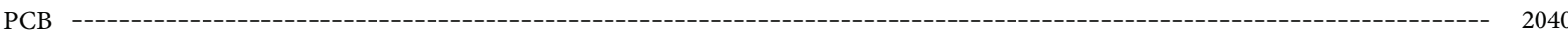

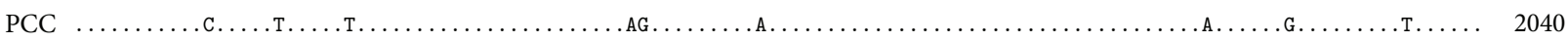

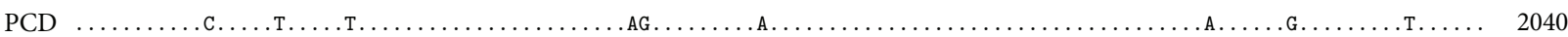

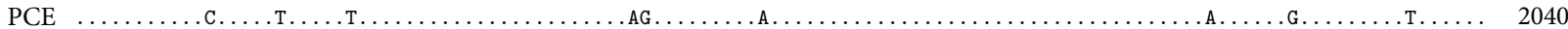

(c)

Figure 3: Continued. 

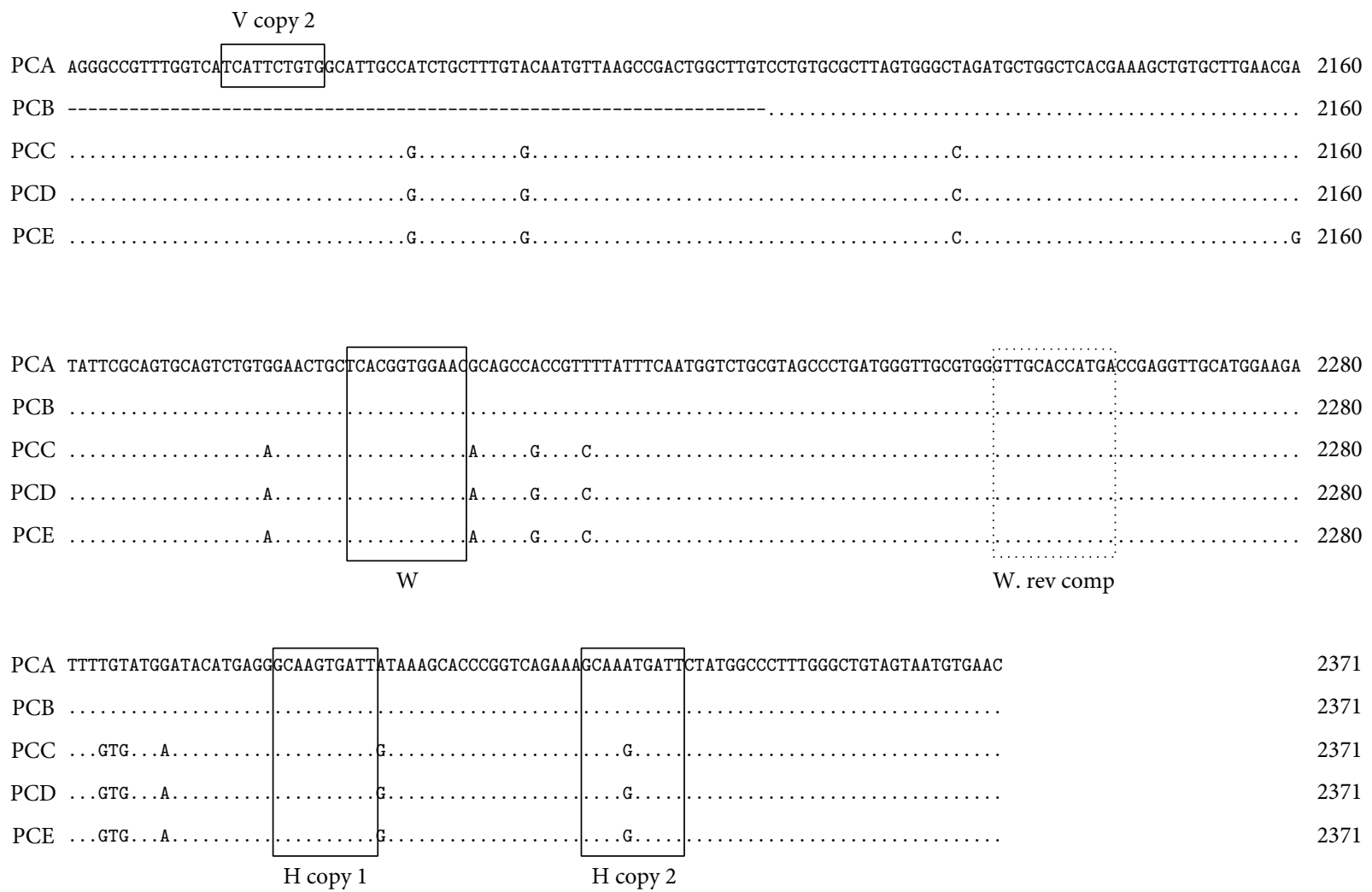

(d)

FIGURE 3: The alignment of intergenic spacer (IGS) rDNA sequences of the five individual Paramphistomum cervi. Dots denote sequence identity to the first sequence. Dashes represent nucleotide deletions.

using tree bisection-reconnection branch swapping were performed for each MP analysis. Bootstrap probability was calculated from 1,000 bootstrap replicates with 10 random additions per replicate in PAUP. A maximum likelihood (ML) analysis was performed using PUZZLE 4.1 [22]. A Bayesian inference (BI) was performed using MrBayes 3.1 [23] with four independent Markov chains run for 1,000,000 metropolis-coupled Markov chain Monte Carlo generations and sampling a tree every 1,000 generations. The consensus tree was obtained after a bootstrap analysis with 1,000 replications with values above $50 \%$ being reported. Phylograms were drawn using the Tree View program version 1.65 [24].

\section{Results and Discussion}

3.1. Complete rDNA Sequences. All five complete rDNA sequences have been deposited in GenBank (accession numbers KJ459934-KJ459938). The lengths of five complete rDNA sequences were 8,493 bp, 9,908 bp, 10,056 bp, 10,167 bp, and 10,221 bp, respectively. The six regions (18S, ITS1, 5.8S, ITS2, 28S, and IGS) of the five complete rDNA sequences are shown in Figure 1.

3.2. 5.8S, ITS2, and $28 S$ rDNA Analyses. There was no variation in the lengths of the 5.8S, ITS2, and $28 \mathrm{~S}$ rDNA regions obtained from five $P$. cervi samples in this study, which were $157 \mathrm{bp}, 286 \mathrm{bp}$, and 4,186 bp, respectively. The intraspecific variations within P. cervi were $0 \%$ for $5.8 \mathrm{~S}$ and ITS2 and $0-0.5 \%$ for $28 \mathrm{~S} \mathrm{rDNA}$. The $\mathrm{G}+\mathrm{C}$ content was $54.14 \%$ for $5.8 \mathrm{~S}, 51.75 \%$ for ITS2, and between $51.74 \%$ and $51.82 \%$ for $28 \mathrm{~S}$ rDNA. The ITS 2 rDNA sequences of the five samples and another stomach fluke from red deer (Cervus elaphus) in Slovakia [9] showed $100 \%$ identity. However, a comparative analysis revealed that the interspecific differences in ITS2 among members of the family Paramphistomatidae were 1.4-6.3\%. Thus, the ITS2 sequence is a useful marker for taxonomic studies of the family Paramphistomatidae at the species level.

Despres et al. found no differences among the ITS2 sequences of $S$. mansoni from several geographical locations in Africa and the western hemisphere [25]. Similar results were reported for E. revolutum, Clonorchis sinensis, and Opisthorchis viverrini [26-28]. Thus, the ITS2 sequence is a useful marker for identifying closely related trematode species.

The present study reported the complete $5.8 \mathrm{~S}$ and $28 \mathrm{~S}$ rDNA sequences, which are the only representative sequences of the family Paramphistomatidae, of $P$. cervi for the first time. Therefore, no interspecific variations were investigated.

3.3. ITS1 rDNA Analyses. The length of the ITS1 rDNA sequences obtained from the five samples was $1,293 \mathrm{bp}$, which 


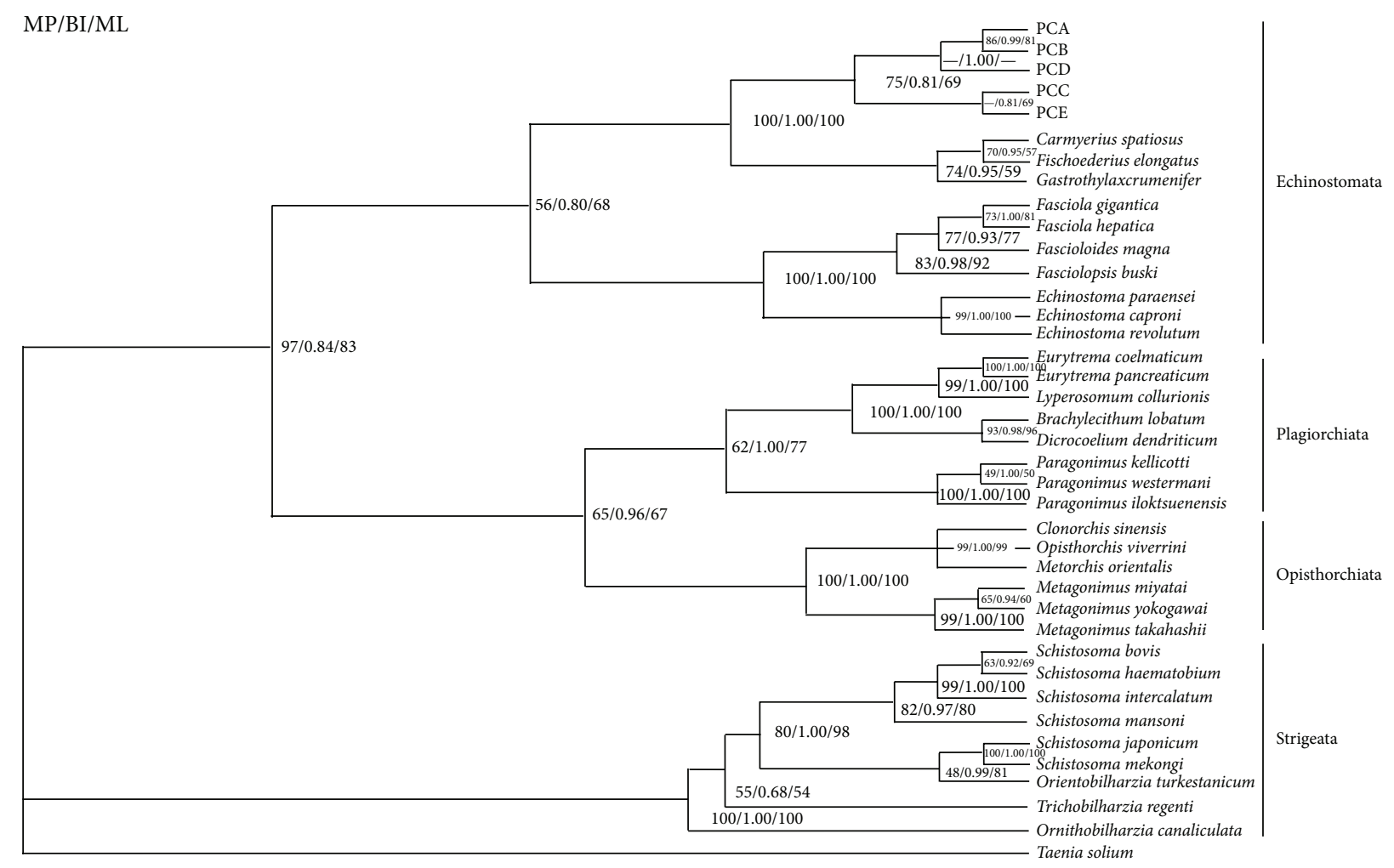

FIGURE 4: Inferred phylogenetic relationship among representative trematodes. The $18 \mathrm{~S}$ rDNA sequences of Paramphistomum cervi were analyzed utilizing maximum parsimony (MP), Bayesian inference (BI), and maximum likelihood (ML), using Taenia solium (GenBank accession number GQ260091) as the outgroup. The numbers along branches indicate posterior probabilities and bootstrap values resulting from different analyses in the order: MP/BI/ML.

was longer than that of other trematodes, such as O. felineus and C. sinensis $[28,29]$. The $\mathrm{G}+\mathrm{C}$ content was $47.72-47.87 \%$, which was lower than that of $C$. sinensis $(54.2 \%)$ [28]. The intraspecific variations within P. cervi were $0-0.4 \%$; thus, the nucleotide diversity in the ITS1 rDNA among the five samples was low. The result was in accordance with that of a study of C. sinensis [28].

It is of interest to note that ITS1 sequence in P. cervi contains repeated sequences with the following characteristics: three copies of a $23 \mathrm{nt}$ complete direct repeat, A, located at $209 \mathrm{nt}$ upstream of the ITS1 sequences; six copies of a $27 \mathrm{nt}$ complete direct repeat, $B$, separated by $1 \mathrm{nt}$, which occur after repeat A; five copies of a 27 nt nearly complete direct repeat, $\mathrm{C}$, separated by $1 \mathrm{nt}$, which occur after repeat $\mathrm{B}$; four copies of a $28 \mathrm{nt}$ complete direct repeat, $\mathrm{D}$; three copies of a $19 \mathrm{nt}$ direct repeat, E; and a $26 \mathrm{nt}$ direct repeat, $\mathrm{F}$ (Figure 2).

Among trematodes, members of the genera Dolichosaccus, Schistosoma, and Paragonimus ITS1 have repeat sequences [30-33] similar to those found in this study. However, other species, such as $S$. japonicum and Paragonimus westermani, contain less repeats $[32,33]$. As mentioned above, the length of the complete ITS1 sequence of $P$. cerv $i$ was longer than that of other trematodes, which is likely related to the number and organization of the repetitive elements.

Previous studies indicated that the ITS2 rDNA was more conserved than ITS1 [30], which may be because of the existence of diverse types and numbers of repeats. The long and short repeats leading to size variation were found across a range of helminthes, including trematodes [32-34], cestodes [35], and nematodes [36], but no length variation was detected in any of the P. cervi samples in the present study.

3.4. Analyses of IGS rDNA Sequences. The $5^{\prime}$ ends of the IGS from the $P$. cervi samples were determined by comparing them with previously published rDNA sequences of schistosomes $[15,37]$. The 3 terminus of the IGS was aligned readily, having relatively few indels and homologous regions in $S$. japonicum [15].

The IGS rDNA of P. cervi had dynamic and highly complex structures. This became apparent upon amplification of the IGS rDNA's PCR products, which varied in length from 2,000 to 3,500 bp (not shown). After the removal of flanking $28 \mathrm{~S}$ and $18 \mathrm{~S} \mathrm{rDNA}$ sequences, the lengths of the five IGS rDNA sequences were $577 \mathrm{bp}, 1,992 \mathrm{bp}, 2,140 \mathrm{bp}$, 2,251 bp, and 2,305 bp, respectively. The $\mathrm{G}+\mathrm{C}$ content was 47.98-50.26\%, and the pairwise sequence differences had a range of $0.2-46.3 \%$. The IGS regions of the five P. cervi samples had strikingly different structures. In contrast to S. intercalatum, S. haematobium, and S. japonicum, the ATrich regions of the five samples were absent, similar to the IGS region of $S$. mansoni $[15,37]$. The IGS rDNAs of $P$. cervi could be roughly divided into two types based on their characteristics (Figure 3 ). The longest one (P. cervi sample 1, 
TABLE 2: Sequences of $18 \mathrm{~S}$ rDNA available in GenBank used to construct phylogenetic relationships among the trematodes.

\begin{tabular}{|c|c|c|c|}
\hline Species & GenBank accession number & Length (bp) & Classification \\
\hline Eurytrema pancreaticum & DQ401034 & 1,857 & Plagiorchiata \\
\hline Eurytrema coelmaticum & DQ401035 & 1,857 & Plagiorchiata \\
\hline Lyperosomum collurionis & AY222143 & 1,945 & Plagiorchiata \\
\hline Brachylecithum lobatum & AY222144 & 1,945 & Plagiorchiata \\
\hline Dicrocoelium dendriticum & Y11236 & 1,950 & Plagiorchiata \\
\hline Paragonimus westermani & AJ287556 & 1,902 & Plagiorchiata \\
\hline Paragonimus kellicotti & HQ900670 & 1,870 & Plagiorchiata \\
\hline Paragonimus iloktsuenensis & AY222141 & 1,860 & Plagiorchiata \\
\hline Metorchis orientalis & JF314771 & 1,901 & Opisthorchiata \\
\hline Opisthorchis viverrini & JF823987 & 1,889 & Opisthorchiata \\
\hline Clonorchis sinensis & JF314770 & 1,902 & Opisthorchiata \\
\hline Metagonimus yokogawai & HQ832632 & 1,867 & Opisthorchiata \\
\hline Metagonimus miyatai & HQ832626 & 1,867 & Opisthorchiata \\
\hline Metagonimus takahashii & HQ832629 & 1,867 & Opisthorchiata \\
\hline Fasciola hepatica & AJ004969 & 1,941 & Echinostomata \\
\hline Fasciola gigantica & AJ011942 & 1,945 & Echinostomata \\
\hline Fascioloides magna & EF534989 & 1,934 & Echinostomata \\
\hline Fasciolopsis buski & L06668 & 1,978 & Echinostomata \\
\hline Echinostoma revolutum & AY222132 & 1,871 & Echinostomata \\
\hline Echinostoma caproni & L06567 & 1,977 & Echinostomata \\
\hline Echinostoma paraensei & FJ380226 & 1,836 & Echinostomata \\
\hline Carmyerius spatiosus & JX518972 & 1,858 & Echinostomata \\
\hline Fischoederius elongatus & JX518979 & 1,859 & Echinostomata \\
\hline Gastrothylax crumenifer & JX518984 & 1,858 & Echinostomata \\
\hline Schistosoma mekongi & AY157228 & 1,880 & Strigeata \\
\hline Schistosoma japonicum & AY157226 & 1,883 & Strigeata \\
\hline Schistosoma haematobium & Z11976 & 1,972 & Strigeata \\
\hline Schistosoma intercalatum & AY157235 & 1,863 & Strigeata \\
\hline Schistosoma bovis & AY157238 & 1,864 & Strigeata \\
\hline Schistosoma mansoni & U65657 & 1,989 & Strigeata \\
\hline Orientobilharzia turkestanicum & AF442499 & 1,909 & Strigeata \\
\hline Trichobilharzia regenti & AY157218 & 1,872 & Strigeata \\
\hline Ornithobilharzia canaliculata & AY157222 & 1,866 & Strigeata \\
\hline Taenia solium (outgroup) & GQ260091 & 2,599 & \\
\hline
\end{tabular}

PCA) and the shortest one, PCB, were considered the same type; the other three samples had the second type. Only PCB contained one 13 nt complete direct repeat (J1 and J2) and one $12 \mathrm{nt}$ incomplete inverted repeat (W and $\mathrm{W}$ reverse complement), which were missing the intervening sequences. PCA exhibited the following features: (1) 11 types (J, K, L, N, $\mathrm{Q}, \mathrm{R}, \mathrm{S}, \mathrm{T}, \mathrm{U}, \mathrm{V}$, and $\mathrm{H}$ ), containing complete and incomplete direct repeats; (2) five types of short and incomplete inverted repeats (only $\mathrm{W}$ and $\mathrm{W}$ rep comp shown); and (3) a complete direct repeat $\mathrm{H}$ and an incomplete inverted repeat $\mathrm{W}$ (W rev comp) were shared by all five $P$. cervi samples. Compared with PCA and PCB, PCC-PCE had the following features: (1) nine types of complete and incomplete direct repeats $(\mathrm{A}, \mathrm{B}, \mathrm{C}, \mathrm{D}$, E, F, G, H, and I); (2) three types of inverted repeats W (W rev comp), O (O rev comp), and P (P rev comp); (3) incomplete inverted repeats $\mathrm{O}$ and $\mathrm{P}$ were only possessed by $\mathrm{PCD}$; and (4) some differences were present in the intervening sequences of PCE. In contrast to the results of previous studies on S. haematobium, S. intercalatum, S. mansoni, and S. japonicum [15, 37], P. cervi was polytype. For example, it contained complete and incomplete direct repeats, as well as incomplete inverted repeats, and no identical direct or inverted repeat was found between the Schistosoma spp. and P. cervi.

Although the lengths and structures of the five IGS rDNA sequences of $P$. cervi were different from one another, some characteristics were similar. For example, the $5^{\prime}$ and $3^{\prime}$ termini of the five $P$. cervi samples' rDNA sequences 
were identical, indicating there were no length variations in this region. Similarly, there were no geographical or individual length variations in this region among samples of S. japonicum from several geographical locations in China [15].

Because no other IGS rDNA sequences of the family Paramphistomatidae were available in GenBank, the interspecific differences were not examined.

3.5. 18S rRNA Sequence Analysis and Reconstruction of Phylogenetic Relationships. The complete $18 \mathrm{~S}$ rDNA sequence of $P$. cervi was determined by a comparison with those of Paragonimus kellicotti (HQ900670) and E. revolutum (GQ463130). The five $18 \mathrm{~S}$ rDNA sequences obtained in this study were all 1,994 bp in length, and the G+C contents were 50.30$50.35 \%$. A pairwise comparison of the aligned sequences was performed using MegAlign, and the comparison indicated that the intraspecific variations within $P$. cervi were between 0 and $0.2 \%$ for $18 \mathrm{~S}$.

The 18S rRNA sequence is useful for studying the phylogeny of members of Digenea [38-40]. Using $18 \mathrm{~S}$ rRNA sequences, the phylogenetic position of $P$. cervi was determined. Using MP, BI, and ML analyses, the phylogenetic relationships among members of trematodes were constructed based on sequences of the $18 \mathrm{~S}$ rDNA sequences available in GenBank (Table 2) without gaps at both ends and with Taenia solium (GQ260091) as the outgroup. Three trees all placed P. cervi within the family Paramphistomatidae, as shown in Figure 4. Two main clades were observed. All the trematodes of Echinostomata, Plagiorchiata, and Opisthorchiata clustered together in one greater clade, and Strigeata clustered in another solitary clade, in accordance with morphological classifications. From the trees, the clade of Echinostomata was divided into two distinct clusters. The P. cervi (PCA-PCE) isolates, Carmyerius spatiosus, Fischoederius elongatus, and Gastrothylax crumenifer formed a tight cluster, while the Fasciolidae and Echinostomatidae occupied the proximate cluster as the sister group. These results indicated that the evolutionary relationship of $P$. cervi was closer to other members of the Paramphistomatidae than to other families (Fasciolidae, Echinostomatidae, Dicrocoeliidae, Paragonimidae, and Opisthorchiidae). The phylogenetic relationships of families within the Digenea were reported previously, indicating there were some discrepancies between the molecular features and some morphological characteristics [41], but this study was an exception.

In conclusion, the present study determined and characterized complete rDNA sequences from $P$. cervi samples for the first time. These results showed that the $5.8 \mathrm{~S}$ and ITS2 rDNA sequences of $P$. cervi were quite conserved, with no within-species variation, but the IGS rDNA displayed the fastest evolutionary rate. These data provided novel and useful genetic markers for studying intra- and interspecific variation of the Paramphistomatidae and provided new sequence data for studying the systematics and phylogenetics of Digenea.

\section{Conflict of Interests}

The authors report no conflict of interests.

\section{Acknowledgments}

This work was supported, in part, by the Scientific Research Fund of Heilongjiang Provincial Science and Technology Department (GZ13B001), the International Science \& Technology Cooperation Program of China (Grant no. 2013DFA31840), and the Science Fund for Creative Research Groups of Gansu Province (Grant no. 1210RJIA006).

\section{References}

[1] I. G. Horak, "Paramphistomiasis of domestic ruminants," Advances in Parasitology, vol. 9, pp. 33-72, 1971.

[2] O. W. Olsen, Animal Parasites: Their Life Cycles and Ecology, Dover, New York, NY, USA; University Park Press, Baltimore, Md, USA, 3rd edition, 1974.

[3] S. A. Bida and T. Schillhorn van Veen, "Enteric paramphistomiasis in Yankasa sheep," Tropical Animal Health and Production, vol. 9, no. 1, pp. 21-23, 1977.

[4] E. Arru, S. Deiana, and P. Muzzetto, "Intestinal paramphistomiasis in ruminants. Experimental infection of sheep with metacercariae and immature forms of Paramphistomum cervi (Schrank, 1790)," Rivista di parassitologia, vol. 31, no. 1, pp. 3342, 1970.

[5] L. J. Rangel-Ruiz, S. T. Albores-Brahms, and J. Gamboa-Aguilar, "Seasonal trends of Paramphistomum cervi in Tabasco, Mexico," Veterinary Parasitology, vol. 116, no. 3, pp. 217-222, 2003.

[6] M. M. Ayaz, M. A. Raza, S. Murtaza, and S. Akhtar, "Epidemiological survey of helminths of goats in southern Punjab, Pakistan," Tropical Biomedicine, vol. 30, no. 1, pp. 62-71, 2013.

[7] C. R. Wang, J. H. Qiu, X. Q. Zhu et al., "Survey of helminths in adult sheep in Heilongjiang Province, People's Republic of China," Veterinary Parasitology, vol. 140, no. 3-4, pp. 378-382, 2006.

[8] H. B. Yan, X. Y. Wang, Z. Z. Lou et al., "The mitochondrial genome of Paramphistomum cervi (Digenea), the first representative for the family paramphistomidae," PLOS ONE, vol. 8, no. 8, Article ID e71300, 2013.

[9] E. Bazsalovicsová, I. Králová-Hromadová, M. Špakulová, M. Reblánová, and K. Oberhauserová, "Determination of ribosomal internal transcribed spacer 2 (ITS2) interspecific markers in Fasciola hepatica, Fascioloides magna, Dicrocoelium dendriticum and Paramphistomum cervi (Trematoda), parasites of wild and domestic ruminants," Helminthologia, vol. 47, no. 2, pp. 76-82, 2010.

[10] E. O. Long and I. B. Dawid, "Repeated genes in eukaryotes.", Annual Review of Biochemistry, vol. 49, pp. 727-764, 1980.

[11] R. S. Dai, G. H. Liu, H. Q. Song et al., "Sequence variability in two mitochondrial DNA regions and internal transcribed spacer among three cestodes infecting animals and humans from China," Journal of Helminthology, vol. 86, no. 2, pp. 245251, 2012

[12] M. Orosová, K. Ivica, B. Eva, and Š. Marta, "Karyotype, chromosomal characteristics of multiple rDNA clusters and intragenomic variability of ribosomal ITS2 in Caryophyllaeides fennica (Cestoda)," Parasitology International, vol. 59, no. 3, pp. 351-357, 2010. 
[13] S. Yamada, A. Yoshida, K. Yoshida et al., "Phylogenetic relationships of three species within the family Heligmonellidae (Nematoda; Heligmosomoidea) from Japanese rodents and a lagomorph based on the sequences of ribosomal DNA internal transcribed spacers, ITS-1 and ITS-2," Japanese Journal of Veterinary Research, vol. 60, no. 1, pp. 15-21, 2011.

[14] C. R. Wang, J. F. Gao, X. Q. Zhu, and Q. Zhao, "Characterization of Bunostomum trigonocephalum and Bunostomum phlebotomum from sheep and cattle by internal transcribed spacers of nuclear ribosomal DNA," Research in Veterinary Science, vol. 92, no. 1, pp. 99-102, 2012.

[15] G. H. Zhao, D. Blair, X. Y. Li et al., "The ribosomal intergenic spacer (IGS) region in Schistosoma japonicum: structure and comparisons with related species," Infection, Genetics and Evolution, vol. 11, no. 3, pp. 610-617, 2011.

[16] J. D. Thompson, T. J. Gibson, F. Plewniak, F. Jeanmougin, and D. G. Higgins, "The CLUSTAL X windows interface: flexible strategies for multiple sequence alignment aided by quality analysis tools," Nucleic Acids Research, vol. 25, no. 24, pp. 48764882, 1997.

[17] T. G. Burland, "DNASTAR's lasergene sequence analysis software.," Methods in Molecular Biology, vol. 132, pp. 71-91, 2000.

[18] K. Tamura, J. Dudley, M. Nei, and S. Kumar, "MEGA4: molecular evolutionary genetics analysis (MEGA) software version 4.0," Molecular Biology and Evolution, vol. 24, no. 8, pp. 15961599, 2007.

[19] P. Rice, L. Longden, and A. Bleasby, "EMBOSS: The European Molecular Biology Open Software Suite," Trends in Genetics, vol. 16, no. 6, pp. 276-277, 2000.

[20] J. N. Betley, M. C. Frith, J. H. Graber, S. Choo, and J. O. Deshler, "A ubiquitous and conserved signal for RNA localization in chordates," Current Biology, vol. 12, no. 20, pp. 1756-1761, 2002.

[21] D. L. Swofford, PAUP*: Phylogenetic Analysis Using Parsimony (and Other Methods). Version 4.0b10, Sinauer Associates, Sunderland, Mass, USA, 2002.

[22] K. Strimmer and A. Von Haeseler, "Quartet puzzling: a quartet maximum-likelihood method for reconstructing tree topologies," Molecular Biology and Evolution, vol. 13, no. 7, pp. 964969, 1996.

[23] F. Ronquist and J. P. Huelsenbeck, "MrBayes 3: bayesian phylogenetic inference under mixed models," Bioinformatics, vol. 19, no. 12, pp. 1572-1574, 2003.

[24] R. D. Page, "TreeView: an application to display phylogenetic trees on personal computers," Computer Applications in the Biosciences, vol. 12, no. 4, pp. 357-358, 1996.

[25] L. Despres, D. Imbert-Establet, C. Combes, and F. Bonhomme, "Molecular evidence linking hominid evolution to recent radiation of schistosomes (Platyhelminthes: Trematoda)," Molecular Phylogenetics and Evolution, vol. 1, no. 4, pp. 295-304, 1992.

[26] J. A. T. Morgan and D. Blair, "Nuclear rDNA ITS sequence variation in the trematode genus Echinostoma: an aid to establishing relationships within the 37-collar-spine group," Parasitology, vol. 111, no. 5, pp. 609-615, 1995.

[27] K. Ando, P. Sithithaworn, C. Nuchjungreed et al., "Nucleotide sequence of mitochondrial COI and ribosomal its II genes of Opisthorchis viverrini in northeast Thailand," The Southeast Asian Journal of Tropical Medicine and Public Health, vol. 32, no. 2, pp. 17-22, 2001.

[28] Y. V. Tatonova, G. N. Chelomina, and V. V. Besprosvannykh, "Genetic diversity of nuclear ITS1-5.8S-ITS2 rDNA sequence in Clonorchis sinensis Cobbold, 1875 (Trematoda: Opisthorchidae) from the Russian Far East," Parasitology International, vol. 61, no. 4, pp. 664-674, 2012.

[29] S. Kang, T. Sultana, V. B. Loktev et al., "Molecular identification and phylogenetic analysis of nuclear rDNA sequences among three opisthorchid liver fluke species (Opisthorchiidae: Trematoda)," Parasitology International, vol. 57, no. 2, pp. 191-197, 2008.

[30] K. Luton, D. Walker, and D. Blair, "Comparisons of ribosomal internal transcribed spacers from two congeneric species of flukes (platyhelminthes: Trematoda: Digenea)," Molecular and Biochemical Parasitology, vol. 56, no. 2, pp. 323-327, 1992.

[31] R. A. Kane and D. Rollinson, "Repetitive sequences in the ribosomal DNA internal transcribed spacer of Schistosoma haematobium, Schistosoma intercalatum and Schistosoma mattheei," Molecular and Biochemical Parasitology, vol. 63, no. 1, pp. 153$156,1994$.

[32] L. van Herwerden, D. Blair, and T. Agatsuma, "Intra-and interspecific variation in nuclear ribosomal internal transcribed spacer 1 of the Schistosoma japonicum species complex," Parasitology, vol. 116, no. 4, pp. 311-317, 1998.

[33] L. Van Herwerden, D. Blair, and T. Agatsuma, "Intra- and interindividual variation in ITS1 of Paragonimus westermani (Trematoda : Digenea) and related species: implications for phylogenetic studies," Molecular Phylogenetics and Evolution, vol. 12, no. 1, pp. 67-73, 1999.

[34] R. Warberg, K. T. Jensen, and J. Frydenberg, "Repetitive sequences in the ITS1 region of ribosomal DNA in congeneric microphallid species (Trematoda: Digenea)," Parasitology Research, vol. 97, no. 5, pp. 420-423, 2005.

[35] J. Bowles, D. Blair, and D. P. McManus, "A molecular phylogeny of the genus Echinococcus," Parasitology, vol. 110, no. 3, pp. 317328,1995

[36] S. A. Subbotin, A. M. Deimi, J. Zheng, and V. N. Chizhov, "Length variation and repetitive sequences of Internal Transcribed Spacer of ribosomal RNA gene, diagnostics and relationships of populations of potato rot nematode, Ditylenchus destructor Thorne, 1945 (Tylenchida: Anguinidae)," Nematology, vol. 13, no. 7, pp. 773-785, 2011.

[37] R. A. Kane and D. Rollinson, "Comparison of the intergenic spacers and 3'end regions of the large subunit (28S) ribosomal RNA gene from three species of Schistosoma," Parasitology, vol. 117, no. 3, pp. 235-242, 1998.

[38] D. Blair and S. C. Barker, "Affinities of the gyliauchenidae: utility of the 18S rRNA gene for phylogenetic inference in the Digenea (Platyhelminthes)," International Journal for Parasitology, vol. 23, no. 4, pp. 527-532, 1993.

[39] D. Otranto, S. Rehbein, S. Weigl et al., "Morphological and molecular differentiation between Dicrocoelium dendriticum (Rudolphi, 1819) and Dicrocoelium chinensis (Sudarikov and Ryjikov, 1951) Tang and Tang, 1978 (Platyhelminthes: Digenea)," Acta Tropica, vol. 104, no. 2-3, pp. 91-98, 2007.

[40] M. Fernandez, D. T. J. Littlewood, A. Latorre, J. A. Raga, and D. Rollinson, "Phylogenetic relationships of the family Campulidae (Trematoda) based on 18s rRNA sequences," Parasitology, vol. 117, no. 4, pp. 383-391, 1998.

[41] J. C. Pearson, "On the position of the digenean family Heronimidae: an inquiry into a cladistic classification of the Digenea," Systematic Parasitology, vol. 21, no. 2, pp. 81-166, 1992. 

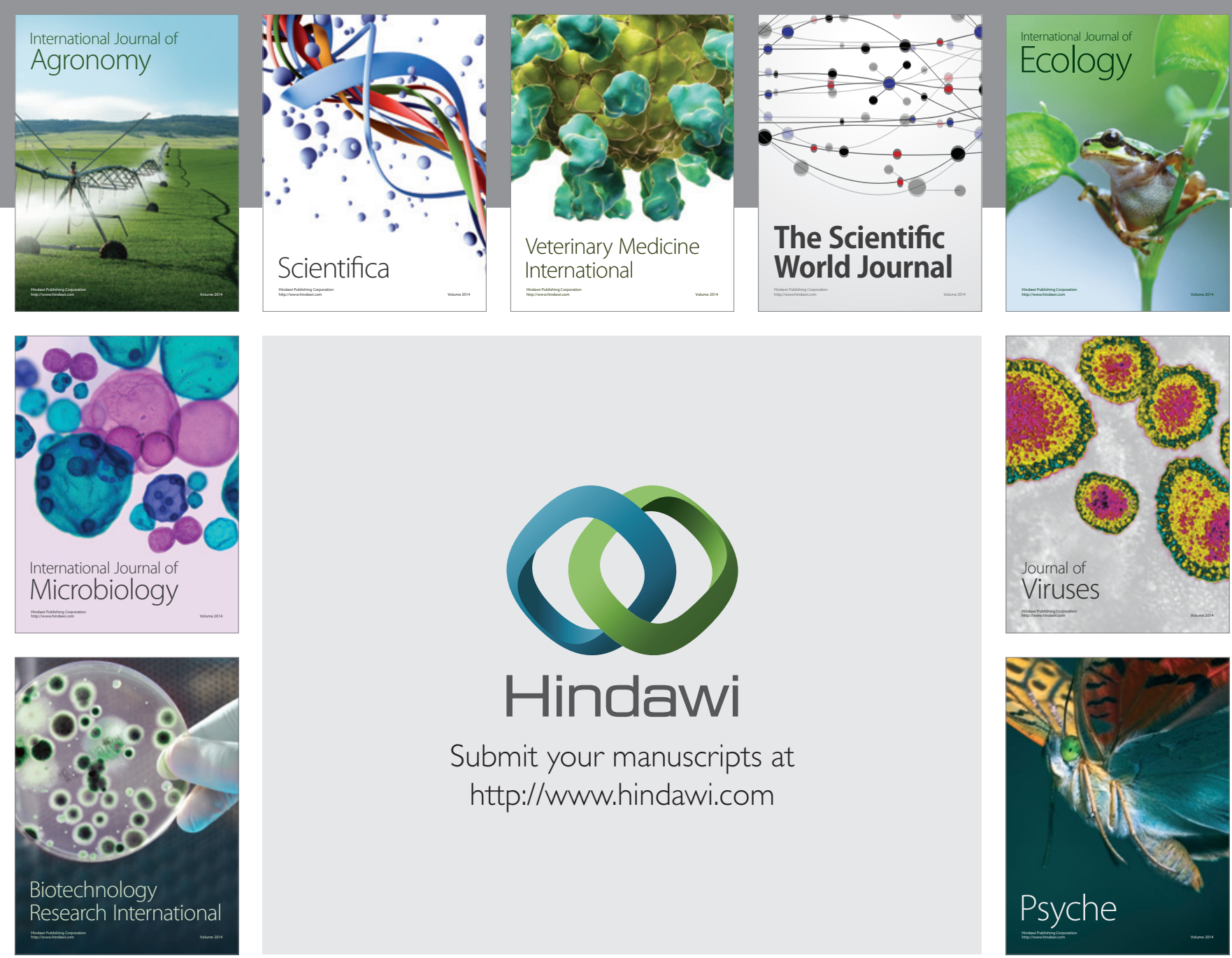

Submit your manuscripts at http://www.hindawi.com
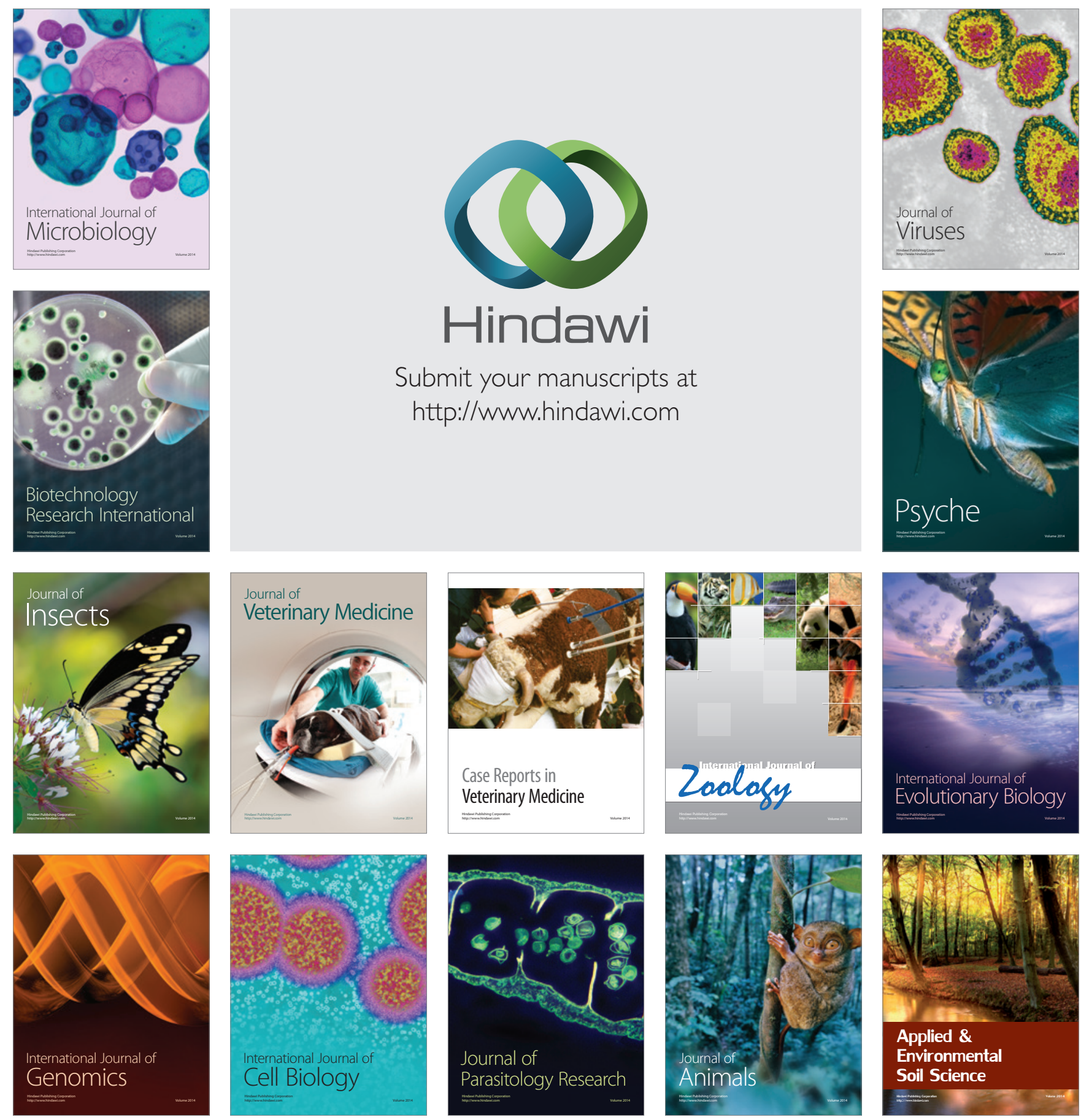